\title{
DEVELOPING A METHOD TO IMPROVE THE ENERGY EFFICIENCY OF MODERN BUILDINGS BY USING TRADITIONAL PASSIVE CONCEPTS OF RESOURCE EFFICIENCY AND CLIMATE ADAPTATION
}

\author{
S. SCHELBACH \\ Department of Resource Efficiency in Architecture and Planning, HafenCity University Hamburg, Germany.
}

\begin{abstract}
Around the world, humans have adapted building forms over the course of centuries to fit external, locally specific parameters such as climate, topography and available building materials. Thus, these structures are generally erected using locally available resources and adapted to fit the regional climate. These concepts were critical in the time before industrialization when neither the building materials, nor the energy and technology necessary for mechanical climate control systems, were available.

Even though numerous studies on the concepts of traditional passive climate control exist, the applicability of these concepts in modern buildings is generally not explored. This study addressed this gap in the research by developing a method as a tool to improve the energy efficiency of modern buildings by integrating traditional passive concepts into the planning process. The paper describes an exemplary investigation of traditional residential buildings in the Upper Town of Thessaloniki, which has been the basis for developing the tool. The results of this case study showed that adding traditional concepts to the current legal requirements would improve indoor comfort and thus building energy performance.

The tool could also be used for educational purposes to make students of the built environment aware of the great diversity of energy efficient heating, cooling and ventilation methods present in traditional buildings. This presents them with the opportunity to practice applying such alternative building designs and make comparisons with the alternatives.

Keywords: building simulation, climate adaptive architecture, natural ventilation, passive climate control, passive cooling, resource efficiency, thermal comfort, vernacular architecture.
\end{abstract}

\section{INTRODUCTION}

The study of traditional architecture presents significant potential as a source of concepts of passive measures to meet indoor comfort demands. But in many regions, vernacular design strategies for achieving thermal comfort conditions have been replaced over the course of time by technical solutions for mechanical climate control. In the best-case scenario, these vernacular design strategies are still known but are in danger of being lost. As described by Vissilia [1], traditional buildings in Sernikai, Greece, are relatively untouched, but additions to the original setup or reliance on technical systems disturb or prevent the traditional concepts for passive climate control. In her study, she demonstrates that the traditional concepts generate climatic benefits superior to new buildings.

As residential buildings currently require about $40 \%$ of the energy consumed overall in the European Union [2], there is great potential to reduce energy consumption by applying passive design concepts. The global population is expected to reach 9 billion by 2050 . Each of those 9 billion people will require adequate housing. Ideally, this need will be met not through growing energy consumption, but rather in a culturally and environmentally sustainable way [3].

In its 10-year strategy for economic advancement, 'Europe 2020', the European Union set the targets of reducing greenhouse gas emissions to $20 \%$ below 1990 levels by 2020, as well as increasing the percentage of renewable energy by $20 \%$ and improving energy efficiency by 
$20 \%$ [4]. To reach these targets, EU member countries were required to define national targets and create national development plans. This reflects the understanding that such targets are not only pursued on an international level but must also be established on a national and regional basis. Vernacular building forms, which make use of passive methods to achieve thermal comfort, could help countries meet these goals.

Information about traditional buildings from around the world has been collected in several works, for example, the especially comprehensive Encyclopedia of Vernacular Architecture of the World by Oliver [5]. This work makes apparent the wide variety of traditional buildings and their adaptations to local conditions but does not show a direct relationship to the present day. A research method to investigate vernacular housing design and evaluate building physics aspects was developed by Nguyen et al. [6] for Vietnam. But this method does not include the application of passive concepts to existing non climate-adapted building stock. Manioğlu and Yilmaz [7] performed a case study of 100 traditional buildings in a hot and dry climate in Turkey and compared their thermal behaviour with a modern building. The results show a neglect of the traditional concept of using the heat storage capacity of the building envelope to avoid overheating and give the advice to use this concept for modern buildings. But the study does not provide the planner with a general method for this kind of evaluation for different situations.

Within this survey, traditional architecture in the Upper Town of Thessaloniki, Greece, was studied to gain knowledge about the concepts used and to develop a step-by-step method for investigating traditional concepts for passive climate control and applying this knowledge to modern buildings [8]. The examined residential buildings, known as Ottoman Houses, developed over a long period within the Ottoman Empire. Ottoman Houses spread throughout the Balkan region $[9,10]$ and regional adaptations were made to fit local conditions.

An initial data collection was carried out by field studies, literature reviews, expert interviews and resident surveys. Initial test results with the building simulation software PRIMERO Komfort 1.1 [11], which is based on Energy Plus, suggested that the use of natural ventilation to minimize overheating in summer months was of paramount importance in the buildings chosen for this study. Wind tunnel experiments with a reference building were conducted to determine the potential for natural ventilation in the study location.

The results of the examinations showed effective concepts of climate adapted architecture concerning natural ventilation, the orientation of the buildings and their openings, shading devices and locally available building materials. To investigate the transferability of these concepts to modern architecture, two case studies were used. This paper explains the developed method by describing each of the five steps in the context of the example.

\section{THE SITE OBSERVATION}

The site observation of the traditional buildings in the Upper Town of Thessaloniki started with field studies and literature reviews, according to step A of the method: 'Site observations' (see Table 2).

\subsection{Examined buildings}

The buildings represent a form of Ottoman House typical of the region, one that began to appear in the rural areas of Northern Greece in the beginning of the 17th century (Fig. 1). The residential buildings, conceived as single-family homes, were generally oriented according to cardinal direction and to optimize available views. Ottoman houses typically had a floor plan 

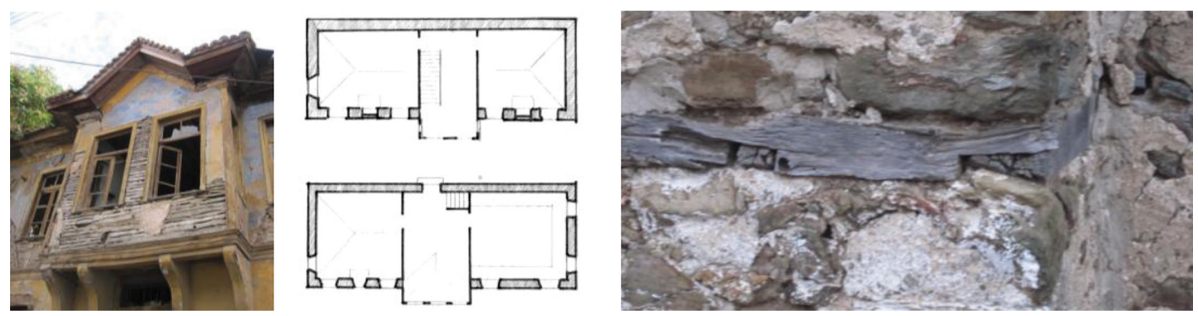

Figure 1: Building in the Upper Town of Thessaloniki (left), typical layout of the upper floor according to Papaiōannou [16] (centre), reinforced masonry with circumferential wooden beams (right).

consisting of three rooms, which divided the house into a central part with a prestigious room for receiving guests and separate women's and men's rooms on both sides. The ground floor was constructed of massive stone and opened out to the garden. The buildings' locations and the accompanying private gardens, in combination with effective natural ventilation, minimized overheating in summer months [12]. One upper floor (typical) or two floors (less common) had walls of a lighter timber frame construction and included the residential living spaces. The central hayat was the central space that connected the other rooms of the house and was used for a variety of purposes. The hayat served as a shaded and well-ventilated room in the summer and buffer zone in the winter. Open variants exist but in the case of the examined buildings, the hayat is a closed living space, expanded with the use of bay windows on the street-facing façade. The buildings were built without cellars and had low-pitched, tiled roofs with an overhang of about $60 \mathrm{~cm}$. Roofs were not constructed with gables or dormers [13]. The originally detached houses are today situated within a dense urban context on a slope facing the sea.

\subsection{Influence of earthquakes}

The buildings in this study are located in a seismically active region in which earthquakes occur not as violent seismic events, but rather with relative frequency at lower magnitudes, remaining an ever-present problem. Thus, the traditional building forms are adapted to the circumstances. Deviating from the building forms typical of Central Europe, the joints of the timber frame construction are secured with tension by inserting metal nails or bolts into predrilled holes [10]. These timber frame joints, combined with the 'shoebox' form of the building, lead to a certain degree of earthquake preparedness. In addition, the stone masonry is reinforced with circumferential wooden beams (Fig. 1, right). This technique is widespread and has been used for at least 5000 years in the Eastern Mediterranean [14,15].

\subsection{The local climate}

Although the Mediterranean climate is often referred to as the 'ideal climate' for humans, high expectations are placed on buildings in Northern Greece. The climate in Thessaloniki is Mediterranean and is influenced little by the continental climate of Eastern Europe. In the spring and autumn, temperatures primarily lie in a range comfortable for humans; however, in the winter temperatures can drop below freezing and precipitation levels increase (January: daily mean temperature $5.5^{\circ} \mathrm{C}$, mean monthly precipitation $39 \mathrm{~mm}$, mean relative humidity 
$75 \%$ ). In the summer, temperatures often exceed comfortable levels (July: daily mean temperature $27^{\circ} \mathrm{C}$, mean monthly precipitation $22 \mathrm{~mm}$, mean relative humidity $52 \%$ ). The mean wind speed is $3 \mathrm{~m} / \mathrm{s}$, generally in the range of $2-6 \mathrm{~m} / \mathrm{s}$ according to the following pattern. At night, there is no or very little wind from the north or east. In the daytime, there is increasing wind from the west or north. In the evening, wind speeds decrease and change to southerly directions. Disturbances of the weather system cause changes to this pattern, leading, for example, to strong and cold wind from the north in winter time.

To deal with the climate conditions, buildings have to be designed to protect occupants from the cold, wind and humidity in the winter as well as prevent overheating in the summer. For this purpose, suitable solutions should be found in the region, when possible. Siting the building with respect to cardinal direction, topography and prevailing winds should help address the challenges. The cubic volume, the ratio of surface area to volume, roof shape, arrangement of windows and openings, shading devices, distribution of building uses and temporary protective devices (against wind and cold in the winter, but also solar radiation in the summer) are possible methods to minimize total energy consumption by maximizing solar gains in the winter and minimizing solar gains in the summer. The surrounding vegetation also plays a role in protecting occupants from overheating in the summer months $[17,18]$. Pergolas covered in climbing plants, especially deciduous grapevines, are used throughout the Mediterranean for shade.

\section{BASIC EVALUATION AND ANALYSIS}

All questions of step A were answered positively, so the study continued to step B, 'Basic evaluation and initial data collection', carried out by field studies, literature reviews, expert interviews and resident surveys. Given that the natural ventilation strategies turned out to be particularly effective, wind tunnel experiments were performed.

A reference building representing a typical Ottoman House in the Upper Town of Thessaloniki was developed for the wind tunnel experiments (Fig. 2). The generated data were used to simulate indoor temperatures in summer and heating demand in winter for the reference building using PRIMERO Komfort 1.1 [11].

The basic evaluation leads to the questions about whether the building design is likely adapted to the local climate and whether passive climate control concepts might be present. In step C of the survey, 'Analysis of the basic evaluation', the passive concepts found through calculations, measurements and building simulations as part of the examination were divided into the four
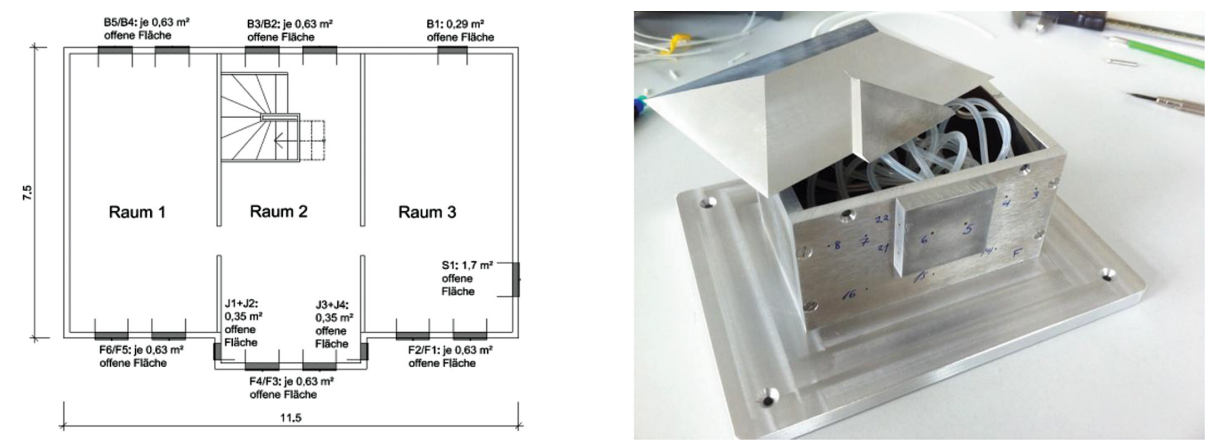

Figure 2: Reference building, upper floor and model for the wind tunnel experiments. 
main topics: (1) natural ventilation, (2) orientation of the buildings and their openings, (3) shading devices and (4) building materials.

\subsection{Natural ventilation}

Experiments to gain knowledge about the natural ventilation of the rooms were carried out in a boundary layer wind tunnel. The reference building was set in the centre of a turntable within different typical settings. The measurements were taken for 12 wind directions of a typical urban wind pattern, according to the boundary conditions defined in VDI 3783 [19] for suburban areas.

The experiments tested the influence of the cubic volume and positioning of openings on natural ventilation rates and showed that the traditional buildings have a high potential for natural cross ventilation driven by pressure differences generated by wind, as shown in Table 1 .

The important ventilation openings are the windows of the upper floor(s), because the upper floor was originally designed for summer use. Air exchange is enabled through a high potential for cross ventilation, which is a result of the floor plan and the orientation of the ventilation openings relative to summer prevailing winds. For the prestigious room, the wind tunnel experiments showed that ventilation is enhanced by the bay windows, which project over the street at the sides of the eaves (see Fig. 3).

Simulated indoor temperatures with different air change rates (ACR) showed that, according to the comfort criteria DIN EN 15251:2012-12 [20], the natural ventilation present in the upper story of the reference building, with the traditional light structure, leads to a comfortable situation in summer for $95 \%$ of the time the rooms are used.

High cross ventilation potential is evident in a comparison between the results of calculations based on values listed in BS 5925-1991 [21] and those based on the measured values from the wind tunnel experiment. The probability of the windows being opened within a comfortable range of the outside temperature is also taken into account (Humphrey's Algorithm [22]). Humphrey's Algorithm was used because nowadays residents rarely use the potential of passive climate control. Both approaches show a similar range of ACRs up to 40/h. The results for buildings in suburban areas, using the values from BS 5925-1991, are in the same range as the wind tunnel experiment results for buildings in a dense, homogeneous group of buildings.

Table 1: Calculated ACR in Room 1, setting 1.1, with one window opened on each side

\begin{tabular}{ccc}
\hline$\Delta \mathrm{c}_{\mathrm{p}}$ & Vf in $\mathrm{m} / \mathrm{s}$ & ACR in $1 / \mathrm{h}$ \\
\hline 0.05 & 5 & 12.5 \\
0.05 & 2 & 5 \\
0.10 & 5 & 18 \\
0.10 & 2 & 7 \\
0.25 & 5 & 28 \\
0.25 & 2 & 11 \\
0.50 & 5 & 40 \\
0.50 & 2 & 16 \\
\hline
\end{tabular}




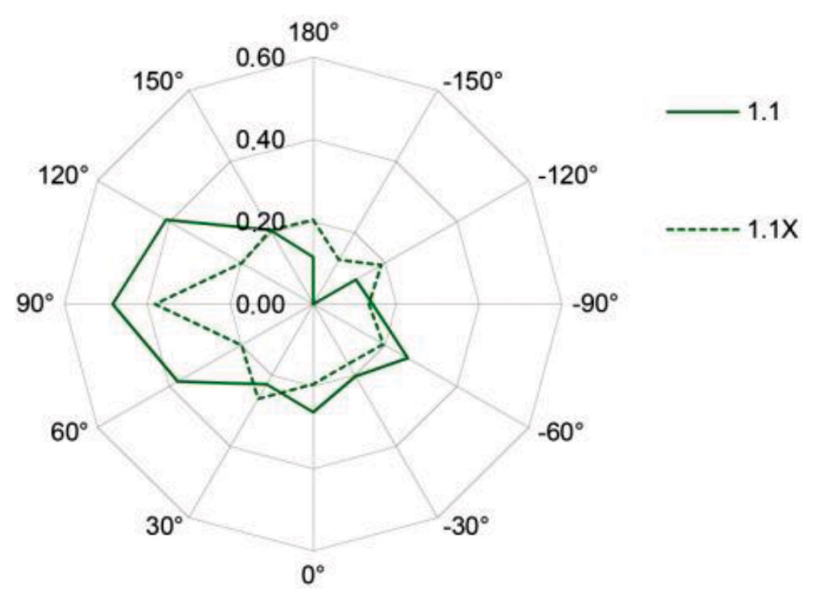

Figure 3: Pressure difference of different wind directions between opposite facades of the reference building comparing the prestigious room with bay windows (1.1) and without (1.1X).

The comparison of different settings of surrounding buildings in the wind tunnel showed that a dense grouping of buildings of similar height appears to have higher ventilation potential than a diverse building cluster. Diverse building clusters experience both areas of higher wind velocities as well as areas with very limited air movement. As only low-pressure differences are needed for sufficient ventilation, high air pressure differentials do not have added value for passive cooling. Increased air pressure does, however, reduce comfort levels by causing unpleasant drafts inside and outside of buildings. In uniform building clusters, airflow appears to be more evenly distributed.

The buildings were also determined to be oriented according to daily and seasonal changes in wind patterns. In the colder months of the year limited ventilation potential is favourable, especially because the exterior walls are not airtight due to the nature of their construction (see Section 3.4). In warmer months, natural ventilation reduces not only risk of overheating of the building interior, but also improves user comfort through high ACR. Sufficient air exchange prevents excessive humidity, high $\mathrm{CO}_{2}$ concentrations and unpleasant odours. The wind tunnel experiments indicate that within the dense, uniform building cluster, wind direction generates both high- and low-pressure differentials. The buildings in this case study have a particularly favourable orientation in terms of the prevailing wind conditions at the site (see Section 3.2).

\subsection{Orientation of the buildings}

In summer as well as in winter, the orientation of openings has a significant influence on temperatures inside the building. In summer, solar radiation can lead to overheating of indoor spaces; in winter solar gains facilitate their heating.

Traditional buildings in the Upper Town are oriented in an east-west direction when possible (Fig. 4). This allows a long façade to the south with wide openings. For the reference building, the simulations showed a potential of twice the solar gains in winter for an eastwest orientation compared to a north-south orientation. Solar gains in summer are half as 


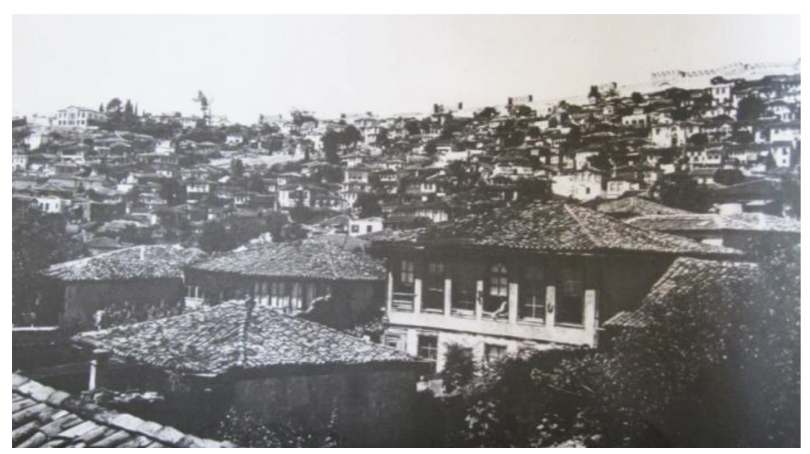

Figure 4: Upper Town of Thessaloniki around 1900, buildings are orientated to the south [23].

high, respectively. This orientation also turned out to be the best alignment concerning natural ventilation, with a long opened façade to the south, facing the sea. Comparing different types of glazing, the simulations showed no reductions in heating demand for the reference building when using double glazing. This is due to lower solar gains compared to single glazing.

\subsection{Shading devices}

To prevent overheating in the summer, it is necessary to minimize direct solar radiation. Shade can be provided by (a) structural elements, (b) surrounding buildings and (c) vegetation. All three shading methods are used in the traditional buildings in the Upper Town of Thessaloniki. As a general rule, the better insulated the exterior walls are, the more effective the shading of the transparent façade surfaces is at preventing overheating in the summer.

Manually operated wooden exterior louvered shutters are used to provide shading for the windows (Fig. 5). This form of shading device allows the user to manipulate indoor temperatures by opening or closing the shutters. However, resident surveys showed a lack of knowledge about making use of this. Because the shutters allow shading without completely blocking natural ventilation, they have an advantage over widely used roller blinds. Building simulations for the reference building showed that the indoor temperature would be below outside temperature on hot days $\left(32^{\circ} \mathrm{C}\right.$ and higher) when shutters are used for shading and there is a high ACR $(7 / \mathrm{h})$. Exterior metal roller blinds lead to higher temperatures indoors than outdoors on hot days due to the blocked ventilation, which is potentially worsened through the need for artificial light. Using curtains or awnings for shading results in indoor temperatures similar to what would be expected when no shading device is used. Curtains and awnings do block a part of the solar radiation, but the fabric heats up quickly and releases thermal radiation to the building interior.

\subsection{Building materials}

For the buildings investigated, locally available materials such as natural stone for the ground floor and bricks, lime, clay and timber for the upper floor(s) were used in the 

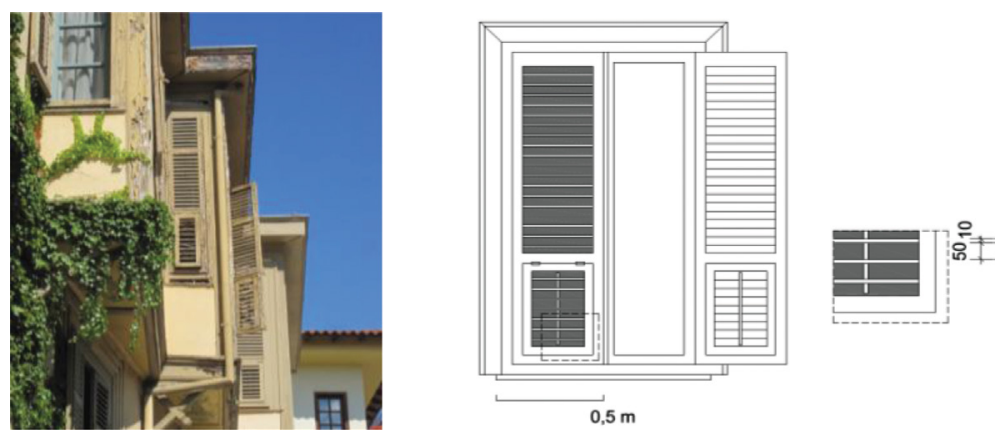

Figure 5: Manually operated wooden exterior louvered shutters.

construction. In the time these buildings were built, the techniques were as efficient as possible and prevented overheating, especially in the living rooms of the upper floor(s) when combined with natural ventilation and shading. Building simulations showed that nowadays the situation could be improved by using modern insulation materials. Installing exterior insulation on the building envelope of the reference building would both reduce overheating in summer as well as energy demand for heating. The light colour of the façades of the traditional buildings reduces risk of overheating in summer. This influence becomes less important as soon as the building has exterior insulation, preventing the structure from being heated up by solar gains.

According to building regulations to protect the historical structure of the Upper Town, new houses are built in the cubic form of the traditional houses, but with concrete replacing the traditional materials and without any insulation materials. Building simulations led to the finding that this leads to very high indoor temperatures. This was confirmed through conversations with residents of such buildings, who complained of uncomfortable temperatures during the summer. The traditional concept relying on cross ventilation and shading only works in combination with the light structure. The computer simulations show that the influence of the building materials on indoor air temperatures is reduced once insulation is applied to the building envelope.

It is surprising that the ceiling of the upper story in traditional buildings evidently had no form of insulation, because thermally insulating this building element would positively affect the room temperatures. However, no evidence of a layer of insulation could be found in the literature, through conversations with experts and homeowners or by inspecting individual buildings. It can then be assumed that no layer of insulation existed. This easy-to-implement measure would reduce indoor air temperatures in the summer and lower the heat demand in the winter.

\section{DERIVATION OF PASSIVE CLIMATE CONTROL CONCEPTS}

After the analysis ( leads to the last step of analysing the applicability of the concepts. The concepts for passive climate control identified in this exemplary examination were divided into four major topics. For all topics, (1) natural ventilation, (2) orientation of the building, (3) shading devices and (4) building materials, all concepts for passive climate control were found and analysed. The evaluation of these topics showed that there are concepts that might be applicable to modern buildings and that the use of natural ventilation has a significant influence. 


\section{APPLICABILITY OF THE IDENTIFIED CONCEPTS}

The applicability of the identified passive climate control concepts was tested on two apartment buildings (Polykatoikia) in Thessaloniki to determine whether the passive climate control concepts identified in the Upper Town might also be applied in an energy-efficient renovation of these existing buildings. Buildings from that time period make up over 50\% of the total building stock in Greece [24,25] and have high heating demand and inadequate protection from summer overheating. Their typical load-bearing structure is a concrete skeleton. The concrete frames are filled with brick masonry. There is no insulation on the façades and the roof. The windows of the building have timber or aluminium frames and single glazing. Typical shading devices are curtains, exterior roller blinds, awnings (of fabric) and balconies extending from the façade.

Building A, a typical six-storey, mixed commercial and residential building in the city centre was built between 1955 and 1973. The residential Building B was built between 1973 and 1980 and is situated in a suburban district of Thessaloniki. Due to a regulation from 1973, it has an open ground floor with columns (Pilotis). This space is used as a parking lot.

The reason for these characteristics is that it became possible over the course of industrialization to construct buildings independent of the site. This led to the loss of vernacular building techniques adapted to suit the local climate. The chosen buildings incorporate no traditional, site-specific building concepts. Even today, the traditional houses in the Upper Town of Thessaloniki are not seen as something from which one could learn. The traditionally constructed buildings have the reputation for being old, poorly insulated buildings, which are gradually torn down anyway or, at best, used as sheds [26].

The building simulation was carried out on critical rooms in the two apartment buildings to test heating demand in the winter and heat gain in the summer (Fig. 6). Through the comparison of multiple simulation variants, retrofitting measures were then assessed individually to determine their effectiveness. Different combinations were tested to form initial generalizations. This allowed for the estimation of the expected relationship between variables. The results were compared with the minimum requirements of the current legislation KENAK D6/B/5825 [27].

\subsection{Building simulations of the case studies}

For the investigation, three rooms of Building A and four rooms of Building B were chosen as the most critical rooms concerning thermal comfort, for example, rooms located to the south, without the possibility of cross ventilation, underneath the non-insulated roof, without external shading or with high internal heat gains. Building simulations were carried out for various combinations of passive measures to understand interactions between different measures. The applied measures show different effects on heating demand and overheating risk.

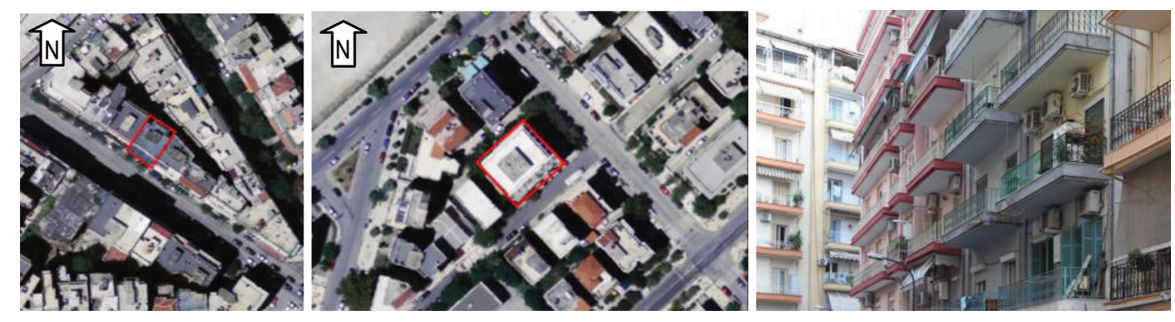

Figure 6: Aerial view of Building A (left), Building B (centre) [28] and typical facades (right) 
Figure 7 shows results for Room B3 on the top floor. The room becomes extremely warm in summer and has a high heating demand. Adding wooden shutters for shading and insulation to the walls and roof provide protection from overheating and significantly lower heating demand. Indoor temperatures in summer can be further reduced by improvements to the ventilation rate. According to the comfort criteria of DIN 15251, this is satisfactory concerning indoor comfort and also reduces the heating demand. Compared to these effects, the impact of changing the glazing is relatively low. For this room, enlarging the transparency ratio of the facade not only lowers the heating energy demand, due to higher solar gains in winter, but also leads to higher indoor temperatures in summer. By contrast, for a room in the same building, but on the first floor, thermal comfort is improved by an enlarged opening, if combined with a concept for natural ventilation. Otherwise, the situation in summer might be unbearable because the heat stored in the heavy construction cannot be released through the exterior building components at night.

Improving the ventilation rate from $1.5 / \mathrm{h}$ (initial situation) to $3 / \mathrm{h}$ (improved) can be achieved by rearranging the floor plan or by adding façade openings to the existing layout to allow for cross ventilation. This has to be combined with the possibility of night ventilation to allow the building to cool down at night. The traditional wooden shutters provide this option because the slats can be adjusted horizontally to improve air movement, while also protecting against weather and burglary. Existing ventilation shafts are another option to enhance natural ventilation. They can be activated with rooftop ventilators.

Comparing the critical rooms in both buildings, the simulations showed that depending on the orientation of the rooms and their location within the building, the interactions and effects of the applied measures show different results. For some rooms, it can be beneficial to add or enlarge windows, leading to lower heating demand and enhanced ventilation. But most rooms with a higher transparency ratio tend to overheat, even if openings are shaded.

To compare the results with the currently valid regulation KENAK, simulations were carried out according to the legal requirements. As visible in Fig. 7, the required measurements

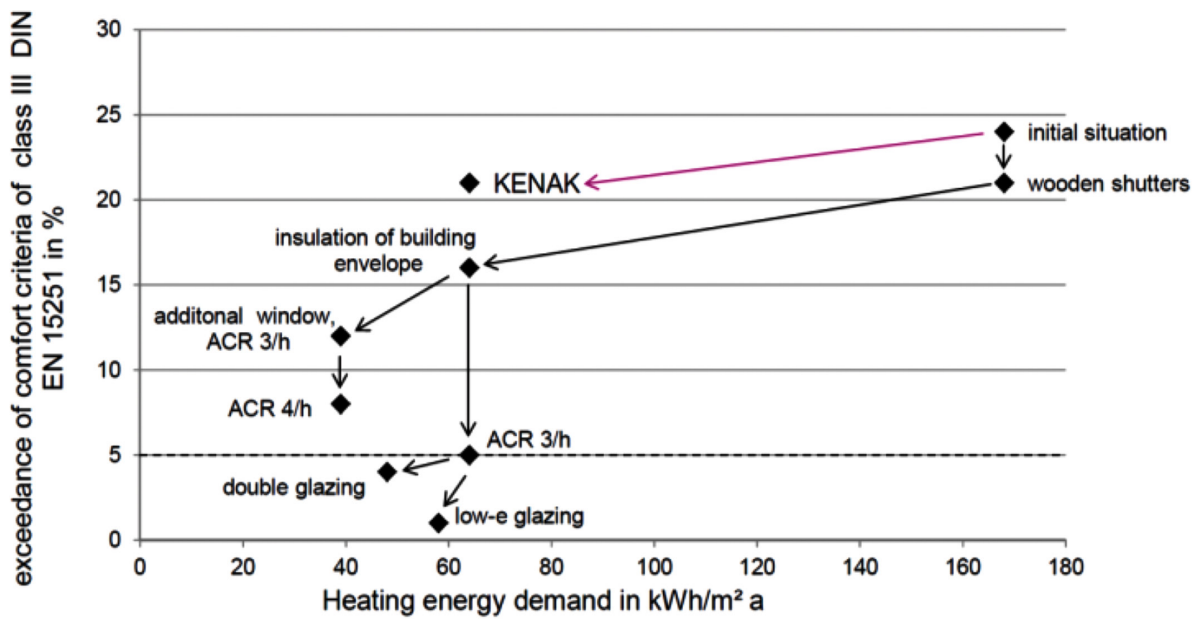

Figure 7: Room B3, upper floor: overheating risk in summer (y-axis) and heating demand (x-axis). 
result in a lower heating demand, but the absence of requirements for natural ventilation and shading lead to overheating in summer.

\section{CONCLUSIONS}

The analyses show that it is possible to reduce baseline heating demand in the tested rooms to one quarter of current levels and meet the requirements of Comfort Class III of DIN 15251 by retrofitting the buildings using passive design concepts. The suggested measure to be taken in every case is the application of external wall insulation. This must be combined with concepts of natural ventilation and shading of openings. A particularly interesting simulation result was that, in this context, retrofitting measures should not be taken in isolation. If, for example, a façade is retrofitted with exterior wall insulation, then indoor thermal comfort conditions worsen in summer if ventilation is not simultaneously improved.

No outstanding advantages to installing low emissivity or insulated glazing compared to single glazing can be found. The impact of this measure, which is a common general recommendation [25,29], should always be examined on a case-by-case basis to determine the precise effects on both heating demand and summer heat gain.

The current regulation KENAK requires only that the U-values of exterior building components be effective at reducing heating demand. But the absence of requirements for shading of openings and natural ventilation does not improve summer indoor temperature conditions, and in some cases the situation may even worsen. The potential for retrofitting using passive design concepts is currently not being exploited; instead technical measures are taken to mechanically cool rooms on the hottest days of the year.

The efficiency of passive concepts depends on user behaviour. The need to mechanically cool the building interior in the summer could be greatly reduced or made completely unnecessary, but only if users are aware of when and why they have to open and close the windows and shading devices to optimally exploit cooling and ventilation potential. If this is not the case, the result is not satisfactory, because concepts of passive design are only as good as they are applied. Further research should be done to investigate the implementation of passive design concepts based on the behaviour and influence of building users. It should also be determined whether residents install air-conditioning units only if room temperatures are too high, or if they also function as a status symbol. This is again a factor that is dependent on the economic climate and could have changed due to the current economic crisis. The experiences from the project 'Pefki Solar Village' in Athens, which has been occupied since the late 1980s, have shown that a strong bond between the building occupants and the building is essential. Passive systems used in the project, which only function when properly serviced by the users, could not operate at full capacity because they were not fully trusted to perform. Despite previous training, for example, the ventilation openings of the Trombe walls were almost always kept closed and thermal mass building elements intended to be used to store solar radiation were obscured by furniture [30].

Additional research is also necessary to understand the effects of applying further combinations of passive concepts. In the context of this study, the only concepts addressed were those identified through the study of traditional buildings in the Upper Town of Thessaloniki and applicable to the retrofitting measures in Polykatoikia.

\section{SUMMARY: A TOOL FOR PLANNERS}

The approach of the whole study is presented graphically in Table 2. It was developed as a method to provide a tool for planners and architects as systematic approach for 


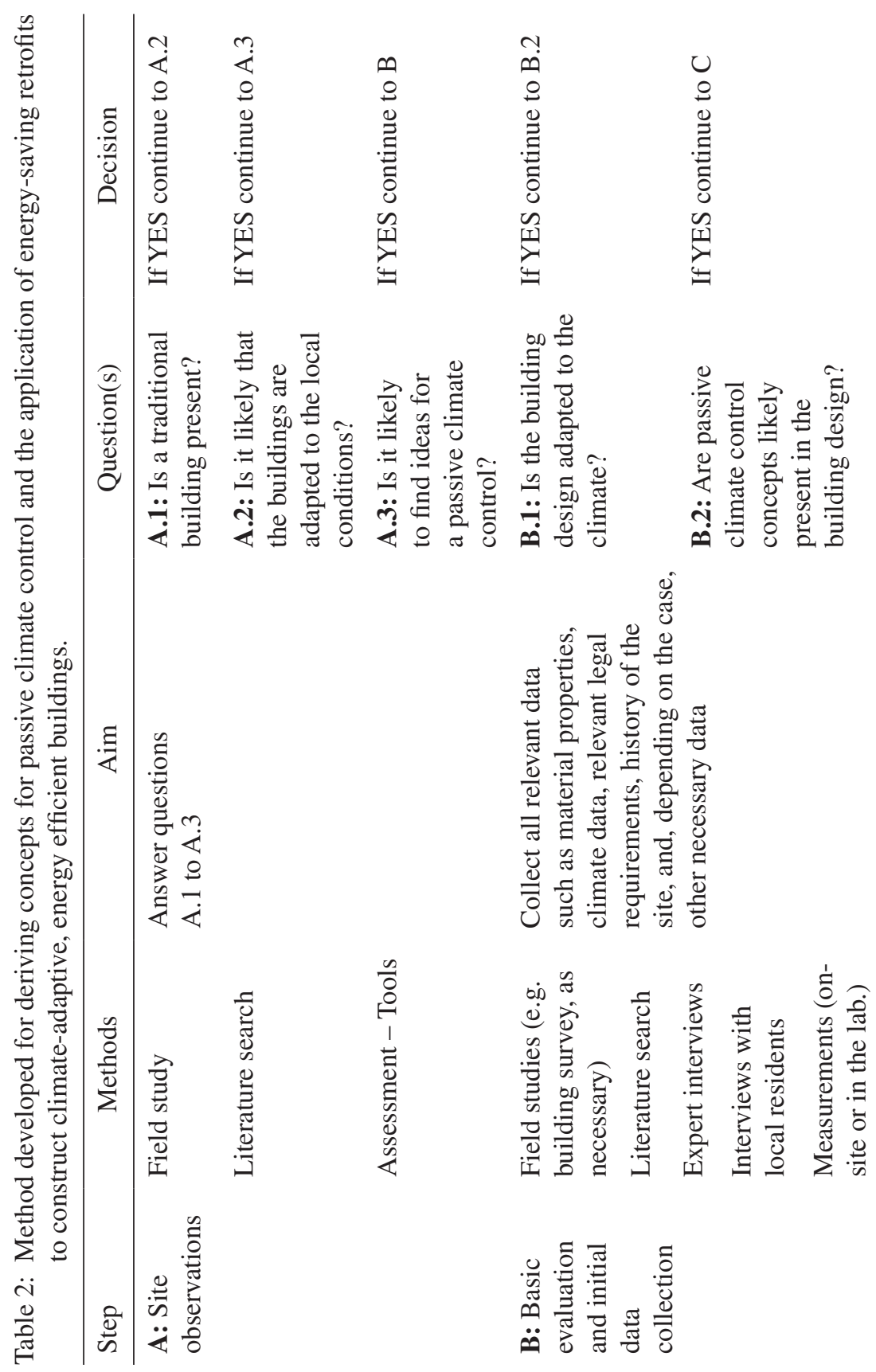




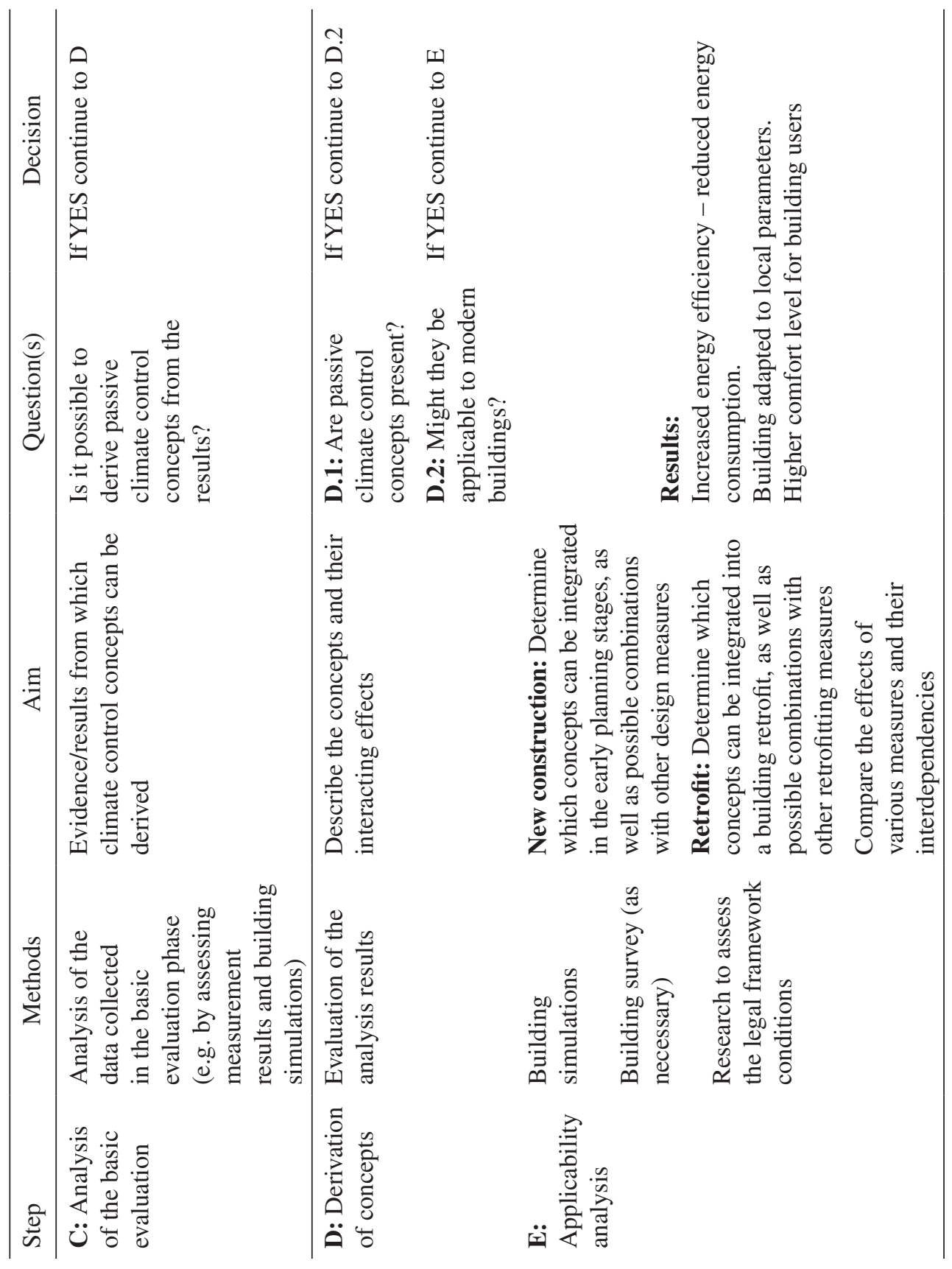


decision-making in five steps and tested within the context of the chosen example of traditional architecture in a city of the Mediterranean region. It can be applied to other locations and climatic conditions. Minor adaptation might be necessary for regions with extreme climate conditions.

Step A is a site observation to investigate whether the building in question is an example of traditional architecture and to identify important aspects to analyse in order to determine whether the building employs climate-adapted and resource efficient construction methods. Step B is the initial data collection. Step C consists of using building simulation software to analyse the data collected. In the next step (D), an evaluation shows whether there are concepts that can be applied to modern buildings. In the last step (E), the application of the measures to a planning process and interactions and interdependencies are investigated.

The method can also be used for teaching purposes to introduce students to the variety of concepts that can be found by studying traditional architecture. It can serve as a tool to help them understand concepts of passive measures to meet indoor comfort demands and determine how to adapt these concepts to modern buildings. It can help students to become aware of the existing built environment of a specific site. They can study building forms that have evolved over the course of centuries and learn to integrate traditional climate control concepts into their designs.

\section{REFERENCES}

[1] Vissilia, A.-M., Evaluation of a sustainable Greek vernacular settlement and its landscape: architectural typology and building physics. Building and Environment, 44, pp. 1095-1106, 2009. doi: http://dx.doi.org/10.1016/j.buildenv.2008.05.026

[2] European Union, RICHTLINIE 2010/31/EU des europäischen Parlaments und des Rates vom 19. Mai 2010 über die Gesamtenergieeffizienz von Gebäuden, L153/13, 2010.

[3] Asquith, L. \& Vellinga, M. (ed.), Vernacular Architecture in the 21st Century, Routledge: London, 2006.

[4] European Commission, EUROPE 2020: A Strategy for Smart, Sustainable and Inclusive Growth, European Commission: Brussels, 2010.

[5] Oliver, P., Encyclopedia of Vernacular Architecture of the World, Cambridge University Press: Cambridge, 1997.

[6] Nguyen, A.-T., et al., An investigation on climate responsive design strategies of vernacular housing in Vietnam. Building \& Environment, 46, pp. 20882106, 2011. doi: http://dx.doi.org/10.1016/j.buildenv.2011.04.019

[7] Manioğlu, G. \& Yılmaz, Z., Energy efficient design strategies in the hot dry area of Turkey. Building and Environment, 43(7), pp. 1301-1309, 2008. doi: http://dx.doi. org/10.1016/j.buildenv.2007.03.014

[8] Schelbach, S., Applying traditional passive concepts of resource efficiency and climate adaptation to improve the energy efficiency of modern buildings: a case study in Thessaloniki, Greece. WIT Transactions on Ecology on the Built Environment, 142, doi: 10.2495/ARC140101. doi: http://dx.doi.org/10.2495/ARC140101

[9] Anastasiadis, A., Thessaloniki. Old Town, Melissa Publishing House: Athens.

[10] Cerasi, M., Bugatti, E. \& D’Agostino, S., The Istanbul Divanyolu. A Case Study in Ottoman Urbanity and Architecture, Ergon Verlag in Kommission: Würzburg, 2004. 
[11] PRIMERO 1.1, Primero Komfort, HCU Hamburg, www.primerosoftware.de.

[12] Mazower, M., Salonica City of Ghosts. Christians, Muslims and Jews 1430-1950, Vintage Books: New York, 2006.

[13] Hatzitrifon, N., Calculation of the response of historical framed walls in South Balkan. Ministry of Culture/EMM-C: Makedonia (not published).

[14] Touliatos, P., The box framed entity and function of the structures: The importance of wood's role. Proceedings of International Seminar on Restoration of Historic Buildings in Seismic Areas, Lesvos Island, Greece, pp. 98-114, 2001.

[15] Vintzileou, E., Effect of timber ties on the behavior of historic masonry. Journal of Structural Engineering, 134(6), pp. 961-972, 2008. doi: http://dx.doi.org/10.1061/ (ASCE)0733-9445(2008)134:6(961)

[16] Papaiōannou, K.S., To Hellēniko paradosiako spiti (The Greek traditional House) (in Greek). Panepistēmiakes Ekdoseis E.M.P.: Athēna, 2003.

[17] Givoni, B., Climate Considerations in Buildings and Urban Design, ITP: USA, 1998.

[18] Hegger, M., Presentation from the university seminar "Mikroklima und Gebäudeumfeld. Pflichtfach klimagerechtes Bauen”, summer term 2010, TU Darmstadt, 2010.

[19] Verein Deutscher Ingenieure, VDI-Richtlinie: VDI 3783 Blatt 12 Umweltmeteorologie - Physikalische Modellierung von Strömungs-und Ausbreitungsvorgängen in der atmosphärischen Grenzschicht - Windkanalanwendungen, VDI-Verlag: Düsseldorf, 2000.

[20] DIN EN 15251:2012-12, Indoor Environmental Input Parameters for Design and Assessment of Energy Performance of Buildings Addressing Indoor Air Quality, Thermal Environment, Lighting and Acoustics; German version, Beuth Verlag, 2012.

[21] British Standards Institution, BS 5925-1991 Code of Practice for Ventilation Principles and Designing for Natural Ventilation, British Standards Institution, 1991.

[22] Rijal, H.B., Humphreys, M.A., et al., Development of an adaptive window-opening algorithm to predict the thermal comfort, energy use and overheating in buildings, Journal of Building Performance Simulation, 1(1), pp. 17-20, 2008. doi: http://dx.doi. org/10.1080/19401490701868448

[23] Moustopoulos, N.C., Ano Poli (in Greek), Melissa Publishing House: Athens, 1979.

[24] Theodoridou, I., Re-Polis $\backslash$ retrofitting Polykatoikia. The case of Mediterranean urban housing typology, Dissertation, Technische Universität Darmstadt, 2012.

[25] Balaras, C.A., et al., European residential buildings and empirical assessment of the Hellenic building stock, energy consumption, emissions and potential energy savings. Building and Environment, 42(3), pp. 1298-1314, 2007. doi: http://dx.doi.org/10.1016/j. buildenv.2005.11.001

[26] Papadopoulos, A.M., Feasibility of energy saving renovation measures in urban buildings. The impact of energy prices and the acceptable payback time criterion. Energy and Buildings, 34, pp. 455-466, 2002. doi: http://dx.doi.org/10.1016/S03787788(01)00129-3

[27] Hellenic Republic, Regulation of Energy Performance of Buildings (KENAK: Kanonismos Energeiakis Apodotikotitas Ktiriwn) D6/B/5825 (in Greek), 2010.

[28] Hellenic Cadastre \& Mapping Agency S.A. 2012, http://gis.ktimanet.gr/wms/con trolpoints/. 
[29] Santamouris, M. \& Asimakopoulos, D.N. (eds), Energy and Climate in the Urban Built Environment, James X James: London, 2001.

[30] Croxford, B. \& Kalogridis, A., Lessons learned from the Pefki solar village in Athens, nearly 20 years on, National Solar Conference Proceedings on Solar 2006: Renewable Energy, Key to Climate Recovery, Campbell-Howe, R., (ed.), American Solar Energy Society: Denver, USA. 